\title{
O projecto do Estatuto do Pessoal Dirigente no âmbito da actual reforma da Administração Pública Portuguesa
}

Revista do

Serviço

Público

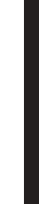

\author{
Luís Miguel Pereira Farinha
}

Ano 54

Número 4

Out-Dez 2003

Quase um quarto de século após a publicação do Decreto-Lei no 191-F/79, de 26 de junho, que estabeleceu o regime aplicável ao pessoal dirigente da função pública, está em curso uma reforma da administração pública portuguesa na qual se inclui, a par de outros projectos ${ }^{1}$, o de um novo regime jurídico para o pessoal dirigente.

O tempo que medeia entre o final da década de 70 do século 20 e o princípio do século 21, acompanhado pelas mudanças políticas, sociais, económicas e tecnológicas de todos conhecidas ${ }^{2}$, determinou a publicação, quanto a esta matéria, de outros dois diplomas, o Decreto-Lei no 323/ 89, de 26 de setembro, e a Lei no 49/99, de 22 de junho, ainda vigente.

Em resultado das mudanças referidas, desde a década de 80 do século passado, grande parte dos estados tem vindo a introduzir reformas no sentido de responder às exigências da sociedade contemporânea.

Numa primeira fase as intervenções reformistas dirigiram-se em muitos países-membros da Organização para a Cooperação e o Desenvolvimento Económico (OCDE) para os três aspectos seguintes:

- Melhoria da eficiência;

- Reforma das práticas de gestão;

- Desinvestimento público em empresas comerciais.

Verificou-se que, como reforma, tais intervenções eram insuficientes, e que não bastaria introduzir e utilizar técnicas e processos próprios da gestão privada para resolver os problemas detectados nas diversas administrações públicas.

Luis Miguel

Farinha é Pós-

Graduado em

Estudos

Europeus pela

Universidade

Católica

Portuguesa e

assessor do

Gabinete do

Ministro da

Agricultura,

Desenvolvimento

Rural e Pescas

de Portugal.

Contato:

1farinha@

madrp.gov.pt 
Com efeito, sabe-se hoje que a criação da capacidade de mudança exige um bom diagnóstico da situação, instrumentos de análise de risco, bom entendimento da cultura própria do funcionalismo público, e do seu papel critico no seio da governança, investigação empírica dos dados relativos à mudança de atitudes, melhores estratégias de intervenção que reconheçam, desde logo, a dificuldade de atingir uma mudança sustentada de comportamento e a necessidade de que a mudança siga uma sequência prevista e planeada ${ }^{3}$.

Esse encontro com as exigências das sociedades dos nossos dias tem levado os políticos, para além da forma como organizam os serviços, a rever as áreas em que o Estado deve intervir e a forma como o faz, v.g., estado prestador, regulador, e fiscalizador ${ }^{4}$.

Na verdade, se com o advento do estado social de direito, o Estado chamou a si a satisfação de um número crescente de necessidades, hoje verifica-se o desinteresse pela satisfação de algumas dessas necessidades, que passam a encontrar novos meios de serem preenchidas, com recurso ao sector privado, através, por exemplo, de parcerias público-privadas, de gestão privada, ou pela privatização de sectores de actividade, sem prejuízo da continuação do recurso ao clássico contrato de concessão ${ }^{5}$.

As actividades que o Estado mantém também são, inúmeras vezes, exercidas de forma diferente; não directamente, mas através de outras pessoas colectivas criadas pelo Estado e a ele pertencentes (administração central indirecta, administração autónoma e administração periférica ${ }^{6}$ ), entidades essas cuja actividade é conformada juridicamente por regimes legais e regulamentares menos rígidos, mais flexíveis.

A complexidade do sistema aumenta ainda com o recurso por partes dessas pessoas colectivas diferentes do estado a vários regimes jurídicos, por vezes em simultâneo, para o enquadramento dos respectivos trabalhadores e dirigentes.

Em Portugal, é hoje comum a contratação simultânea de trabalhadores segundo o regime da função pública ${ }^{7}$ (nomeação, contrato administrativo de provimento e contrato de trabalho a termo certo) e regimes de direito privado.

Quanto aos dirigentes, há os que exercem as suas funções segundo regimes de direito público privativo ${ }^{8}$, com sujeição ao regime jurídico do pessoal dirigente da função pública e outros que, estão submetidos ao Estatuto do Gestor Público ${ }^{9}$, sem prejuízo de inúmeras situações híbridas, em que se aplicam, à mesma pessoa, normas de ambos os regimes.

A actividade da Administração Pública portuguesa, designadamente a actividade desenvolvida pelos seus órgãos e agentes, está constitucionalmente sujeita aos princípios da igualdade, proporcionalidade, justiça e imparcialidade. 
Além destes princípios, os dirigentes estarão, ainda, estatutariamente sujeitos aos princípios da transparência e da boa-fé ${ }^{10}$.

A acrescer a estes princípios, todos designados no projecto do Estatuto do Pessoal Dirigente, daqui em diante designado por projecto, como "princípios gerais de ética", os dirigentes, relativamente à gestão, ficam também obrigados a pautar a sua actuação por critérios de igualdade, eficácia, eficiência, simplificação de procedimentos, cooperação, comunicação eficaz e aproximação ao cidadão ${ }^{11}$.

Também neste âmbito há uma aproximação ao constitucionalmente previsto quanto à estrutura da Administração, que deve evitar a burocratização e deve aproximar os serviços das populações.

Acresce que, a Constituição prevê que a lei assegurará a racionalização dos meios a utilizar pelos serviços, para o que o diploma legal que resultar do projecto de que se cuida pode contribuir de modo significativo.

De acordo com o projecto, passará a recair sobre os dirigentes, por força da lei, o dever de concretizar muito do que o legislador constitucional previu quanto à estruturação da Administração.

A simplificação dos procedimentos, a eficiência e mesmo a cooperação, expressamente previstas no projecto, parecem poder reconduzir-se "à estruturação de modo a evitar a burocratização", tanto mais que a alguns dirigentes compete "organizar a estrutura interna do serviço ou organismo, designadamente, através da criação, modificação ou extinção de unidades orgânicas flexíveis, e definir as regras necessárias ao seu bom funcionamento, articulação e, quando existam, formas de partilha de funções comuns ${ }^{12}{ }^{13}$.

O dirigente passa, portanto, a ser responsável por garantir que, no funcionamento da respectiva unidade orgânica, desaparecem "interesses próprios, alheios à legitimação democrática, divorciados dos interesses das populações "(...) rotina e demora na resolução dos assuntos dos cidadãos, compadrio na selecção de pessoal etc" ${ }^{14}$.

Além destes princípios constitucionais, na análise do projecto importa atender à situação presente ${ }^{15}$, às linhas de orientação aprovadas pelo governo para a reforma da administração pública que são as seguintes ${ }^{16}$ :

1. prestigiar a missão da Administração Pública e os seus agentes na busca da exigência e da excelência;

2. delimitar as funções que o Estado deve assumir directamente daquelas que, com vantagem para o cidadão, melhor podem ser prosseguidas de forma diferente ${ }^{17}$;

3. promover a modernização dos organismos, qualificando e estimulando os funcionários, inovando processos e introduzindo novas práticas de gestão;

4. introduzir uma nova ideia de avaliação dos desempenhos, seja dos serviços, seja dos funcionários; 
5. apostar na formação e na valorização dos novos funcionários públicos.

Importa, agora, analisar mais detalhadamente o projecto de Estatuto dos Dirigentes da Administração Pública que o governo apresentou em setembro de $2003^{18}$.

Começando pelo preâmbulo, ressalta, desde logo que o dirigente é entendido como "o factor de aliança entre os objectivos das políticas públicas e o envolvimento e a capacidade dos serviços e organismos".

Aos dirigentes compete, essencialmente, a:

1. coordenação e continuidade dos processos de mudança;

2. organização e os métodos de trabalho;

3. exigência crítica na simplificação e racionalização de processos;

4. abertura à gestão e partilha de conhecimentos;

5. sensibilidade e iniciativa para a formação do pessoal e reconhecimento de competências.

A missão cometida ao pessoal dirigente permite conhecer um pouco melhor a figura tal como se apresenta no projecto.

Neste, a todo o pessoal dirigente ${ }^{19}$ é conferida a missão de prosseguir as atribuições cometidas ao respectivo serviço, assegurando o seu bom desempenho.

O bom desempenho é conseguido por dois meios, que são interdependentes; de um lado a optimização dos recursos disponíveis, designadamente os humanos, os financeiros e os materiais $\mathrm{s}^{20} \mathrm{e}$, do outro, a satisfação dos administrados, destinatários da actividade prosseguida pelo respectivo serviço ou organismo. Tudo isto, ao abrigo da lei, do programa do Governo e das determinações recebidas pelos dirigentes dos membros do Governo 2122 .

Por se tratar de uma distinção nova, agora apresentada pelo legislador, com importantes reflexos na disciplina jurídica aplicável, importa atender à inovação que se traduz na divisão dos cargos dirigentes em duas categorias, a saber, os cargos de direcção superior, que inclui os de director-geral e de subdirector geral e equiparados, e os de direcção intermédia que integra os directores de serviço e os chefes de divisão ${ }^{23}$.

A importância da distinção tem que ver com três aspectos, nomeadamente:

1. o nível hierárquico;

2. as competências;

3. as responsabilidades cometidas.

Começando pelo nível hierárquico mantêm-se os quatro níveis que vêm desde 1979, agora divididos em cargos de direcção superior e de direcção intermédia de nível 1 e 2, respectivamente, como atrás se referiu.

O legislador não estabeleceu qualquer regra quanto à possibilidade de um serviço ou organismo não dispor na sua estrutura hierárquica de 
um ou mais destes níveis de cargos dirigentes, nem estabelece qualquer regra relativa às condições mínimas normalmente exigíveis para a existência de um dirigente ou da respectiva unidade orgânica, nem para a criação ou manutenção destes ${ }^{24} 25$.

Uma vez que os objectivos da reforma da Administração Pública em curso se concretizam, de forma gradual e consistente, em torno de três eixos, um dos quais é a organização do Estado e da Administração, poder-se-ia, porventura, prever, a título transitório ou definitivo, que o afastamento das regras de natureza quantitativa a que se alude acima seria admitido a título excepcional, devidamente fundamentado.

Dirão, porventura, alguns que, dependendo a renovação da comissão de serviço dos titulares de cargos de direcção superior dos resultados evidenciados no respectivo exercício ${ }^{26}$, e tendo estes competências para organizar a estrutura interna do serviço, através da criação, modificação ou extinção de unidades orgânicas flexíveis, não poderão deixar de atender à racionalidade baseada nos critérios propostos ou noutros mais adequados à organização do serviço ou organismo, atentas as suas atribuições e os meios disponíveis. Tanto mais que aos dirigentes é exigível o respeito pelos princípios de gestão legalmente consagrados e o uso efectivo das competências que lhes são conferidas.

Na verdade, só a aplicação continuada do diploma a que o projecto vier a dar origem permitirá verificar a aplicação da lei, a prática dos serviços e organismos e, portanto, avaliar a opção do legislador, neste e noutros aspectos.

Sem embargo, a observação da prática recente da generalidade dos dirigentes dos serviços e organismos da Administração Pública fornece elementos que, em nossa opinião, aconselham a introdução dos critérios de natureza quantitativa atrás referidos, ou de outros que tenham objectivos semelhantes.

No que se refere às competências e às inerentes responsabilidades $^{27}$, parece que a grande distinção entre os cargos de direcção superior e os de direcção intermédia está no modo de acompanhamento da respectiva unidade orgânica, na proximidade com o pessoal, e com a prática dos actos que determinam os administrados a procurarem o serviço ou organismo.

A confiança, desde logo pelas exigências objectivas agora introduzidas no que respeita à formação e ao modo de recrutamento, também se afigura uma marca de distinção entre os providos em cargos de direcção superior e intermédia, a que se voltará mais adiante.

Efectivamente, a definição das grandes linhas condutoras e delimitadoras do funcionamento dos serviços e organismos são reservadas para os directores-gerais e sub directores-gerais. 
Ao director de serviços cabe condução do próprio pessoal numa perspectiva não "pessoalizada" e, aos chefes de divisão compete assegurar a boa qualidade do trabalho técnico realizado, a gestão do saber técnico e mesmo científico que, cada vez mais, fundamenta as decisões da Administração Pública ${ }^{28}$.

Importa, ainda, referir que os titulares dos cargos de direcção superior de $2^{\circ}$ grau, sub directores-gerais e equiparados, têm as competências que lhes forem delegadas ou subdelegadas, a que acrescem as que lhes sejam expressamente atribuídas pelo diploma orgânico ou estatutário do respectivo serviço ou organismo ${ }^{29}$.

Vejamos, então, a titulo exemplificativo, algumas competências dos titulares dos cargos de direcção superior ${ }^{30}$ :

1. elaborar os planos anuais ou plurianuais de actividades com identificação dos objectivos a atingir pelos serviços, os quais devem contemplar medidas de desburocratização, qualidade e inovação;

2. assegurar, controlar e avaliar a execução dos planos de actividades e a concretização dos objectivos propostos;

3. elaborar os relatórios de actividades com indicação dos resultados atingidos face aos objectivos definidos, bem como o balanço social nos termos da lei aplicável;

4. elaborar os projectos de orçamento de funcionamento e de investimento, tendo em conta os planos de actividades e os programas aprovados;

5. elaborar e aprovar a conta de gerência;

6. superintender na utilização racional das instalações afectas ao respectivo serviço ou organismo, bem como na sua manutenção conservação e beneficiação.

De modo diferente, quanto aos titulares de cargos de direcção intermédia, o legislador distingue, no que se refere a competências, os dirigentes de primeiro grau dos de segundo grau ${ }^{31}$.

$\mathrm{O}$ director de serviços tem competências que não se afiguram bem definidas, parece que faz a ponte entre os cargos de direcção superior e as previstas para os chefes de divisão.

Efectivamente, sendo certo que ao director de serviços cabe definir os objectivos de actuação da respectiva unidade orgânica, tendo em conta os objectivos gerais estabelecidos, bem como controlar e avaliar o desempenho e a eficiência dos serviços dependentes, com vista à execução dos planos de actividades e à prossecução dos resultados obtidos e a alcançar, etc. , é ao chefe de divisão que a lei dá as competências mais importantes pela proximidade com o pessoal no domínio e pela visibilidade junto dos utentes.

Assim, tendo em conta as competências que o projecto atribui ao chefe de divisão, grande parte da percepção dos efeitos da reforma da Administração Pública pelos cidadãos passa necessariamente pelo modo 
como forem interiorizadas e postas em prática pelos chefes de divisão as medidas adoptadas.

A importância dos titulares de base dos cargos dirigentes facilmente se alcança pelo elenco de algumas competências que lhes são conferidas, nomeadamente, nos seguintes domínios:

1. da qualidade técnica do trabalho produzido;

2. do apoio e motivação do pessoal;

3. da divulgação de informação e da prestação de formação ${ }^{32}$;

4. do levantamento das necessidades de formação profissional;

5. da avaliação do mérito dos funcionários.

Passando, agora, para as exigências de formação específica para o exercício de cargos dirigentes, importa assinalar inovações, que são diferentes consoante se trate de cargos de direcção intermédia e de direcção superior.

Exigindo-se a todos os titulares de cargos dirigentes o perfil, a experiência e os conhecimentos adequados ${ }^{33}$, como aliás se verificava já nos anteriores e no actual Estatuto do Pessoal Dirigente, introduzem-se agora no projecto exigências formativas mais rigorosas para o pessoal de direcção intermédia do que para o pessoal de direcção superior.

A formação é entendida como uma necessidade que se faz sentir continuamente - ao longo da vida - prevendo-se a garantia da permanente actualização no domínio das técnicas de gestão e o desenvolvimento das competências através do sistema de formação profissional, assim como da participação em congressos, seminários, colóquios e palestras ${ }^{34}$.

Para o pessoal de direcção intermédia, sem prejuízo do regime transitório previsto ${ }^{35}$, passa a ser exigida a aprovação em curso específico de Alta Direcção em Administração Pública ${ }^{36}$.

Acresce que o legislador prevê, neste caso, as áreas de competência sobre as quais incide essa formação profissional específica, a saber:

1. organização e actividade administrativa;

2. gestão de pessoas e liderança;

3. gestão de recursos humanos, orçamentais, materiais e tecnológicos;

4. informação e conhecimento;

5. qualidade, inovação e modernização;

6. internacionalização e assuntos comunitários.

O curso a que se aludiu é assegurado, no âmbito da Administração Pública, pelo Instituto Nacional de Administração, sendo o respectivo regulamento e condições de acesso objecto de portaria do membro do Governo que, em cada momento, for responsável pela área da Administração Pública.

Este curso pode, ainda, ser ministrado por outras entidades, designadamente, instituições do ensino superior e entidades formadoras. 
Quanto ao acesso a este curso haverá que atender, por um lado, aos princípios constitucionais especialmente aplicáveis à função pública, e, por outro, ao número e à qualidade dos candidatos admitidos e formados, isto é, há que ter presente que a Administração Pública - assim como a sua elite - visa a prossecução do interesse público.

Concretizando, na apresentação das candidaturas e na selecção dos candidatos, importa garantir a aplicação dos princípios da igualdade e da imparcialidade, assegurando que a ninguém é vedado o acesso aos cursos, a não ser por critérios objectivos que encontram a sua fundamentação na prossecução do interesse público.

De um ponto de vista complementar ao referido, dever-se-á, em cada momento, dispor apenas do número de dirigentes em formação e já formados que seja efectivamente necessário à satisfação das necessidades dos serviços e organismos da Administração Pública, à correcta gestão destes recursos humanos, sem que os mesmos sejam escassos, nem demasiado numerosos para os cargos dirigentes efectivamente necessários, previstos nas leis orgânicas e nos estatutos dos serviços e organismos.

No que se refere ao recrutamento são também de assinalar as alterações previstas no projecto.

O recrutamento para os cargos de direcção intermédia é feito de entre funcionários dotados de competência técnica e aptidão para o exercício de funções de direcção, coordenação e controlo que possuam uma licenciatura, que tenham frequentado como aproveitamento o Curso de Alta Direcção em Administração Pública e possuam experiência profissional de quatro ou seis anos em carreiras, para cujo provimento seja exigível a licenciatura, consoante se trate de recrutamento cargo de chefe de divisão ou de director de serviços.

Já para os cargos de direcção superior o recrutamento é feito por escolha, de entre indivíduos licenciados, vinculados ou não à administração pública, que possuam competência técnica, aptidão, experiência profissional e formação adequadas ao exercício da função.

O requisito da licenciatura pode ser afastado pelas leis orgânicas ${ }^{37}$.

Para o pessoal de direcção superior que não seja possuidor de formação específica, exige-se a frequência de um seminário especializado no início do exercício de funções ${ }^{38}$.

Quanto a estes, os critérios para o recrutamento assentam em larga medida na confiança de que forem merecedores junto dos membros do governo, a qual se funda no prévio conhecimento, no reconhecimento ou em recomendações.

Em relação ao regime vigente, o da Lei no 49/99, de 22 de junho, a mudança a assinalar é efectivamente a da previsão da frequência de um seminário especializado. 
É que, importa assinalar, o regime actualmente em vigor introduziu o concurso como método de selecção do pessoal dirigente que hoje é classificado de direcção intermédia, excluindo deste método de selecção os dirigentes de topo, a que correspondem hoje os cargos de direcção superior.

Mantém-se, portanto, no projecto a confiança como critério decisivo na escolha dos dirigentes, designadamente, dos directores gerais e dos subdirectores gerais e equiparados.

Recapitulando, sem embargo de se prever a frequência de um seminário pelos dirigentes superiores, no início das suas comissões de serviços, as únicas diferenças a assinalar são efectivamente ao nível dos cargos de direcção intermédia, e reconduzem-se ao seguinte:

1. a necessidade de frequentar um curso específico para o exercício de funções dirigentes;

2. o desaparecimento do concurso previsto na Lei no $49 / 99$, no Estatuto do Pessoal Dirigente vigente.

Importa, portanto, aguardar pela aplicação da lei a que o projecto der origem para verificar qual o significado dos novos preceitos na prática dos serviços, desde logo, qual a sua contribuição para a reforma, para a escolha de dirigentes líderes, responsáveis, com mérito e qualificações para o exercício das respectivas funções.

A este propósito importa atender à prática recente das nomeações para cargos dirigentes.

No ano de 2000, mais de $65 \%$ dos dirigentes (em exercício de funções) eram maiores de 50 anos, com altas qualificações do ponto de vista académico, o que não significa necessariamente qualificações no domínio da gestão pública, provenientes em cerca de $90 \%$ dos casos do interior da própria administração pública, tendo cerca de $56 \%$ das pessoas feito carreira no Ministério em que exercia funções como dirigente ${ }^{39}$.

Tendo em conta estes e outros dados disponíveis, verifica-se a necessidade de, na aplicação da lei, criar as condições para que exista renovação e mobilidade na administração pública.

A este propósito, importa criar normas jurídicas que, por força da introdução do contrato individual de trabalho não possam, em casos concretos, criar dificuldades à mobilidade, nem que seja indirectamente.

Com efeito, no caso do contrato individual de trabalho, não existe norma que preveja a mudança de quadro como se verifica para os funcionários públicos, por exemplo, através da transferência, que

“(...) consiste na nomeação do funcionário sem prévia aprovação em concurso para lugar vago do quadro de outro serviço ou organismo, da mesma categoria e carreira ou de carreira diferente 
desde que, neste caso, se verifique a identidade ou afinidade de conteúdo funcional e idênticos requisitos habilitacionais (...)" ${ }^{\prime 40}$,

e da permuta, que se reconduz à nomeação recíproca e simultânea de funcionários pertencentes a quadros de pessoal de serviços ou organismos distintos ${ }^{41}$.

É que, a requisição e a transferência, por se aplicarem sempre a casos de exercício de funções a título transitório, podem em muitos casos não se revelar os instrumentos mais adequados ${ }^{42}$, designadamente no que se refere aos chefes de divisão, que têm uma actividade em que a componente técnica é mais significativa e, por isso, podem uma vez terminadas as funções dirigentes ter interesse em continuar a trabalhar na mesma área.

Acrescem, ainda, as limitações normalmente resultantes dos critérios de selecção previstos para cada concurso, que privilegiam o conhecimento e a experiência de matérias muito específicas, concedendo por essa via uma posição de clara vantagem aos funcionários do quadro a que pertence o lugar posto a concurso.

Por outro lado, a interacção com o sector privado, que é praticamente inexistente, deve ser encorajada, sob pena de a incompreensão e a desconfiança mútuas persistirem, com prejuízo para todos.

Não parece, no entanto, que o projecto contenha alguma disposição que vise, em especial, criar condições propiciadoras dessa interacção. Mesmo nos casos em que se trata de permitir que um funcionário público exerça transitoriamente funções no sector privado, para o que se continuará, por certo, a recorrer à figura da licença sem vencimento ${ }^{43}$.

O provimento nos cargos de direcção continua a ser feito em comissão de serviço, por três anos, tal como se verifica desde 1979 .

O legislador não aponta razões para a manutenção deste período de tempo, que, portanto, parece não ter sido questionada no âmbito da elaboração do projecto.

A renovação da comissão de serviço, por sua vez, vê a sua disciplina alterada, desde logo, por se prever a sua avaliação ${ }^{44}$.

Em primeiro lugar, nos cargos de direcção superior, a renovação da comissão de serviço passa a depender dos resultados evidenciados no respectivo exercício, a que respeita o relatório dos resultados obtidos e a síntese da aplicação do sistema de avaliação do respectivo serviço, a elaborar pelo dirigente ${ }^{45}$.

Neste aspecto, afigura-se-nos como muito importante a prática que vier a ser seguida, pois há o risco sério de o relatório e a avaliação se poderem tornar uma formalidade despida de qualquer interesse prático.

Tanto mais que, para os cargos de direcção intermédia, a renovação da comissão de serviço depende "da análise circunstanciada do respectivo desempenho e dos resultados obtidos," o que é feito com base no processo 
de avaliação do dirigente cessante e no relatório por este apresentado, relativo às actividades prosseguidas e aos resultados obtidos.

Seria de prever, pelo menos em alguns casos, por amostragem, nos primeiros tempos de vigência da lei resultante deste projecto, um processo de aconselhamento e monitorização das actividades prosseguidas ${ }^{46}$ ?

No caso dos dirigentes superiores, portanto directores gerais e subdirectores gerais e equiparados, prevê-se a limitação do exercício do mesmo cargo a três renovações, limitação não prevista para os dirigentes intermédios.

Várias razões se podem aduzir a favor desta solução, desde logo, a selecção dos dirigentes intermédios ser precedida de publicitação na Bolsa de Emprego Público ${ }^{47}$, e a renovação da comissão de serviço estar dependente da análise circunstanciada do desempenho e dos resultados obtidos, como atrás se referiu ${ }^{48}$.

Por outro lado, não se vislumbra qual a desvantagem que idêntica solução - limitação do número de renovações possíveis da comissão de serviço - pode apresentar quanto à sua aplicação aos cargos de direcção intermédia.

Esta limitação do número de comissões de serviço, prevista no projecto apenas para os dirigentes de nível superior, deveria ser estendida também aos de nível intermédio.

Deste modo, propiciar-se-ia a mobilidade dos directores de serviços e dos chefes de divisão, dando-lhes em consequência uma visão geral mais abrangente da própria Administração Pública, o que, aliado à sua formação específica em gestão, poderia fazer aparecer a médio e a longo prazo, um corpo de dirigentes altamente qualificado, com experiência diversificada em várias áreas técnicas de actuação, isto é, uma verdadeira elite administrativa.

Assim, poder-se-ia, em alternativa, ter adoptado solução diferente, a aplicar a todos os dirigentes independentemente do respectivo nível, a saber:

1. quatro anos de duração da comissão de serviço, coincidente com a legislatura ${ }^{49}$;

2. limite máximo de duas renovações (doze anos de exercício de funções);

3. nos órgãos de direcção colegiais, ou nos casos em que existe um director-geral e um ou mais subdirectores gerais prever a cessação de todas as comissões de serviço simultaneamente com a do director geral.

Tendo em conta a necessidade de formação na área de gestão pública dos dirigentes intermédios, e da reafirmação da confiança pessoal e política nos dirigentes superiores, a previsão de comissões de serviço de 
duração correspondente a quatro anos, coincidente com a legislatura, poderia trazer várias vantagens, designadamente as seguintes:

1. maior coesão da equipas, nas relações entre os seus membros, e nas relações com terceiros, designadamente o governo e as organizações da sociedade civil;

2. maior estabilidade no funcionamento dos serviços com o alargamento dos prazos de validade das soluções de organização interna dos serviços e organismos ${ }^{50}$;

3. aumento da responsabilização dos dirigentes e dos membros do governo que os nomeiam;

4. maior visibilidade dos resultados da gestão;

5. diminuição do grau de desconfiança relativamente à nomeação dos dirigentes, em especial no início das legislaturas;

6. aumento de planificação em sintonia com os programas do governo e as efectivas exigências dos serviços tendo em vista as necessidades públicas a satisfazer.

Outra alteração introduzida respeita à eliminação da figura da suspensão da comissão de serviço, responsável pela eternização de situações precárias ${ }^{51}$.

Quanto a este aspecto, formulam-se duas notas.

Em primeiro lugar, afigura-se positivo o desaparecimento da norma que actualmente prevê a suspensão da comissão de serviço no caso em que o dirigente tomava posse num de entre um elevado número de cargos públicos, expressamente previstos na lei.

Há que exigir maior rigor, disponibilidade e profissionalismo no exercício dos cargos dirigentes, sendo certo que a todos é conferida a possibilidade, o direito de, no momento por si considerado oportuno, mudar de actividade, desde logo, assumir cargos de natureza política, electivos ou não.

E, uma visão sistemática do regime jurídico do funcionalismo público $^{52}$ assim o exige. Com efeito, a lei vigente prevê que, através da nomeação, se visa assegurar o exercício profissionalizado de funções próprias do serviço público que revestem carácter de permanência ${ }^{53}$. Ao invés, a comissão de serviço é aplicável a situações de carácter transitório ${ }^{54}$.

Logo, afigura-se adequado que o pessoal que exerce funções dirigentes conserve o direito ao lugar de origem e não possa ser prejudicado na sua carreira profissional por causa do exercício das suas funções, relevando para todos os efeitos no lugar de origem o tempo de serviço prestado naquele cargo, o que se verifica no Estatuto do Pessoal Dirigente vigente. 
A segunda nota, para referir que os preceitos do projecto parecem ter sido desenhados tendo em vista o exercício de cargos dirigentes por pessoal vinculado à função pública, não para detentores de vínculos jurídico-laborais hoc sensu, quer se encontrem ao serviço da Administração ou de outros sectores de actividade, v.g., privado ou cooperativo. Tanto no que se refere ao espírito, como à letra do preceito, que usa o termo funcionário.

Haverá que encontrar mecanismos que possam garantir um tratamento de acordo com o princípio da igualdade para todos os que pretendam apresentar candidaturas ou venham a exercer cargos dirigentes, independentemente da natureza do vínculo que os liga, ou não à Administração Pública.

Tendo, nomeadamente, em conta que este regime jurídico dos dirigentes se pretende aplicar à administração central indirecta (v.g. aos institutos públicos), parece que seria preferível a utilização do conceito "trabalhadores da função pública", já consagrado a nível constitucional"55.

Analisados alguns aspectos da proposta do Novo Estatuto do Pessoal Dirigente, o qual introduz alterações em aspectos essenciais do regime, designadamente, quanto à formação, ao recrutamento e aos direitos e deveres dos dirigentes, como se viu, importa agora aguardar pela sua efectiva aplicação à Administração Pública, e pela interpretação que dos novos preceitos vier, em concreto, a ser feita pelos serviços e organismos, bem como pelos Tribunais.

Tendo em consideração a importância da matéria que o projecto trata, que é estruturante no que se refere à composição e à renovação da "elite administrativa", assim como ao contexto em que é introduzido, fazendo parte de um pacote legislativo vasto, não será, por certo, possível, sem o decurso de alguns anos, fazer uma avaliação da sua importância enquanto instrumento de reforma e de mudança, ao serviço dos objectivos da presente reforma. 
1 São do domínio público os projectos do Estatuto do Pessoal Dirigente, da Lei Quadro dos Institutos Públicos, bem como os anteprojectos da Lei de Avaliação do Desempenho na Administração Pública, do Decreto Regulamentar relativo à Avaliação do Desempenho na Administração Pública e do diploma que tem por objecto o Contrato de Trabalho na Administração Pública, todos disponíveis em www.sgmf.pt

2 Quanto à presente reforma, importa ter igualmente em conta as dificuldades financeiras que o país atravessa, as quais, relativamente à gestão de pessoal, determinaram fortes restrições quanto à contratação, as quais constam da Resolução do Conselho de Ministros no 97/2002, de 18 de Maio e do Despacho Conjunto nº 643/2002, dos Secretários de Estado do Orçamento e da .Administração Pública.

3 Neste sentido, vide Public Sector Modernisation, Policy Brief, in OECD Observer, Outubro de 2003, www.oecd.org/publications/Pol_brief.

4 A propósito da definição dos serviços de interesse geral, vide Vincenti-Mitchener, Daniela, Social, Social Services Terra Incognita e Fischbach-Pytell, Balanced European Union means a Social Market Economy in The Parlament Magazine, n. ${ }^{\circ}$ 168, 6 de Outubro de 2003, págs. 35 e seguintes. Na perspectiva da reforma da Administração Pública Brasileira, vide Pereira, Bresser, De la Administración Burocrática a la Gerencial, in bresserpereira.ecn.br, em que se analisa a proposta de reforma do aparelho de Estado a partir da sua divisão em quatro sectores; o núcleo estratégico do Estado; as actividades exclusivas do Estado; os serviços não exclusivos ou competitivos; a produção de bens e serviços para o mercado.

5 “....as pessoas colectivas de direito privado (e até algumas de direito público) podem ser incumbidas por outras pessoas de direito público, nos termos da lei, de exercer funções públicas, como é o caso mais frisante, das concessionárias do domínio público, de serviços públicos ou de obras públicas" im Caetano, Marcello, Manual de Direito Administrativo, vol. I, 10ª edição, Coimbra, Almedina, 1980.

6 Sobre estes conceitos vide Amaral, Diogo Freitas do, Curso de Direito Administrativo, vol. I, 1a edição, Coimbra, Almedina, pág. 203 e segs.

7 Os princípios gerais em matéria de emprego público, remunerações e gestão de pessoal da função pública estão previstos no Decreto-Lei no $184 / 89$, de 2 de Junho.

${ }^{8}$ Cfr. o no 5 do artigo $1^{\circ}$ da Lei no 49/99, de 22 de Junho.

9 Cfr. o Decreto-Lei no 464/82, de 9 de Dezembro.

${ }^{10} \mathrm{Cfr}$. o artigo 4을 do Projecto de Estatuto do Pessoal Dirigente com o no 2 do artigo $266^{\circ}$ da Constituição.

${ }^{11}$ Cfr. O no 3 do artigo 6o do projecto com os n⿳o 2 e 3 do artigo 267o da Constituição.

${ }^{12} \mathrm{Cfr}$. a alínea f) do no 1 do artigo 7 o do projecto.

${ }^{13}$ A este propósito ver ainda a alínea e) do no 1 do artigo 7o do projecto, que prevê a competência de propor ao membro do Governo a prática dos actos de gestão do serviço para os quais o dirigente não tenha competência própria ou delegada.

${ }^{14}$ In Canotilho, J.J.Gomes e Moreira, Vital, Constituição da República Portuguesa, Coimbra, Coimbra Editora, 3ª edição revista, pág. 927.

${ }^{15}$ Quanto a este aspecto, que não se analisa neste artigo, vide Farinha, Luís Miguel Pereira, Dirigente Hoje (o), comunicação apresentada no $1^{\circ}$ Congresso Nacional da Administração Pública, INA, Lisboa, 2003.

${ }^{16}$ Cfr. o no 1 da Resolução do Conselho de Ministros no 95/2003, de 30 de Julho. 
${ }^{17} \mathrm{Na}$ ponderação das funções que o Estado pode ou deve alienar não se pode deixar de atender a um conjunto vasto de critérios pois, para além da eficiência, importa considerar os interesses estratégicos do Estado, as consequências a nível económico e social, os quais não permitem tomar decisões apenas com a consideração dos efeitos mais próximos, ou dos mais imediatos.

${ }^{18}$ Vide www.min-financas.pt.

${ }^{19}$ Adiante se verá a qualificação dos dirigentes.

${ }^{20} \mathrm{O}$ combate aos desperdício de recursos públicos é um dos princípios essenciais da reforma, como se refere expressamente no preâmbulo da RCM 95/2003.

${ }^{21}$ As determinações dos membros do Governo não podem deixar de atender aos poderes que a lei lhes confere, sendo, pela própria natureza das coisas, diferentes nos casos em que há poder de direcção, tutela ou superintendência.

${ }^{22}$ A este propósito, importaria verificar se o legislador não disse menos do que queria na parte final da alínea d) do oํ 1 do artigo $7^{\circ}$ quando refere unicamente os poderes de direcção.

${ }^{23}$ Cfr. o artigo $2^{\circ}$ do projecto.

${ }^{24}$ Em relação a este aspecto, vide o no 1 do artigo 8 o do projecto quanto às competências dos titulares de direcção intermédia do 1ํgrau, directores de serviços.

${ }^{25}$ Sobre as novas tendências estruturais vide Lopes, Carlos Alberto Mendes, Estratégias de Gestão Empresarial na Administração Pública, in Renovar a Administração Pública: Um Imperativo, Instituto Superior de Ciências Sociais e Políticas, pág. 134 e segs..

${ }^{26} \mathrm{Cfr}$ o $\mathrm{n}^{\mathrm{o}} 3$ do artigo $22^{\circ}$ do projecto.

${ }^{27} \mathrm{O}$ termo responsabilidade não é aqui usado stricto sensu, tal como se verifica no artigo $15^{\circ}$ do projecto, no qual se prevê que, no exercício das suas funções, os titulares de cargos dirigentes são responsáveis civil, criminal, disciplinar e financeiramente. Quanto ao apuramento destas responsabilidades e à defesa dos titulares dos cargos dirigentes, assinala-se que, nos termos do artigo 23으, o Estado garante aos dirigentes um regime de assistência e patrocínio judiciário diferente do previsto para a general idade dos cidadãos, regime este de que beneficiam igualmente os membros do Governo pelos actos praticados no exercício das respectivas funções.

${ }^{28}$ Sobre este aspecto vide Otero, Paulo, Conceito e Fundamento da Hierarquia Administrativa, Coimbra Editora, Coimbra, 1992, pág. 286 e seguintes.

${ }^{29}$ Cfr. o no 5 do artigo 7o do projecto. A lei, designadamente o no 2 do artigo $35^{\circ}$ do Código do Procedimento Administrativo, já prevê que através de um acto de delegação de poderes, os órgãos competentes para decidir em determinada matéria podem sempre permitir que o seu imediato inferior hierárquico, adjunto ou substituto pratiquem actos de administração ordinária nessa matéria.

${ }^{30} \mathrm{Cfr}$. o artigo $7^{\circ}$ do projecto.

${ }^{31} \mathrm{Cfr}$. o artigo $8^{\circ}$ do projecto.

${ }^{32} \mathrm{Cfr}$. o artigo $11^{\circ}$ do projecto.

${ }^{33} \mathrm{Cfr}$. o no 1 do artigo $11^{\circ}$ do projecto .

${ }^{34} \mathrm{Cfr}$. os no ${ }^{\mathrm{O}} \mathrm{2}$ e 3 do artigo $11^{\circ}$ do projecto

${ }^{35} \mathrm{Cfr}$ o artigo $35^{\circ}$ do projecto, que visa assegurar a garantia dos direitos adquiridos.

${ }^{36}$ Cfr. a alínea b) do no 1 do artigo 20 o do projecto.

${ }^{37} \mathrm{Cfr}^{3}$ o $\mathrm{n}^{\mathrm{o}} 3$ do artigo $20^{\circ}$ do projecto.

${ }^{38} \mathrm{Cfr}$. o preâmbulo do projecto.

${ }^{39}$ In Elites Administrativas e Mudança Política em Portugal, Nunes Filipe Abreu, comunicação apresentada no 1ํㅡㄹ Congresso Nacional da Administração Pública, INA, Lisboa, 2003. 
${ }^{40}$ Cfr. o artigo 25 do Decreto-Lei no 427/89, de 7 de Dezembro e, o Decreto-Lei no 175/98, de 2 de Julho, quanto às transferências entre a administração central e a administração local.

${ }^{41}$ Cfr. o artigo $26^{\circ}$ do diploma referido na nota anterior

${ }^{42} \mathrm{Cfr}$. 27을 do diploma referido nas duas notas antecedentes.

${ }^{43}$ A licença de vencimento, expressamente prevista nos artigos $73^{\circ}$ e seguintes da Lei $\mathrm{n}^{\circ}$ 100/99, de 31 de Março, apresenta cinco modalidades, com tempos de duração e efeitos diferentes. Este diploma aplica-se aos funcionários e agentes da Administração Pública.

${ }^{44}$ A este propósito importa chamar a atenção para os artigos 17ํㅡ e 18ํㅡㅁ da proposta de Lei que cria o Sistema Integrado de Avaliação do Desempenho na Administração Pública (SIADFAP), onde se prevê, separadamente, a avaliação dos dirigentes e a avaliação dos serviços e organismos.

${ }^{45}$ Cfr. o artigo $22^{\circ}$ do projecto.

${ }^{46}$ A proposta de Lei que cria o SIADAP prevê no seu artigo 19a a criação de uma base de dados com fins de controlo permanente e avaliação do sistema.

${ }^{47}$ Cfr., o $\mathrm{n}^{\mathrm{o}} 1$ do artigo $21^{\mathrm{o}}$ do projecto.

${ }^{48}$ Cfr. o Decreto-Lei no 78/2003, de 23 de Abril e www.bep.gov.pt.

${ }^{49}$ Não parece consistente a crítica que aponta ser esta uma solução que levaria necessariamente à politização da Administração Pública, em especial dos cargos dirigentes, atendendo à prática corrente, e à verificação de que, desde 1979, o critério de escolha dos titulares destes cargos, legalmente previsto, sempre foi o da escolha, logo da confiança. Acresce que as exigências de formação previstas para os titulares de cargos de direcção intermédia e o novo sistema de avaliação poderem acrescentar-se aos instrumentos que podem contribuir para diminuir a força do argumento da politização da Administração Pública.

${ }^{50}$ Diminuiria, por certo, a tentação de introduzir continuamente alterações às leis orgânicas e aos estatutos.

${ }^{51} \mathrm{Cfr}$. o artigo $28^{\circ}$ do projecto.

${ }^{52}$ Sobre os direitos dos funcionários públicos e dos agentes sujeitos ao mesmo regime jurídico, vide, Alfaia, João, Direitos dos funcionários, in Dicionário Jurídico da Administração Pública, vol. IV, Lisboa, 1991.

${ }^{53}$ Cfr. o no 2 do artigo 6o do Decreto-Lei no 184/89, de 2 de Junho.

${ }^{54}$ Cfr., o artigo 7ํ do Decreto-Lei no 427/89, de 7 de Dezembro.

${ }^{55}$ Cfr. o no 1 do artigo 269o da Constituição. 
O projecto do Estatuto do Pessoal Dirigente no âmbito da actual reforma da Administração Pública Portuguesa

\section{Luís Miguel Pereira Farinha}

Este artigo analisa as alterações ao regime jurídico dos dirigentes da função pública portuguesa, que constam da proposta apresentada pelo Governo.

Mencionam-se, ainda, as limitações verificadas e os princípios orientadores da reforma.

Em seguida, analisam-se de um ponto de vista crítico alguns aspectos, designadamente, a missão do dirigente, as categorias e os níveis, as competências, a formação, o recrutamento e a selecção, o provimento, a duração das comissões de serviço e a sua renovação.

Por fim, aponta-se a importância de monitorar a aplicação da lei, tendo em vista verificar o seu papel na mudança.

\section{El proyecto del Régimen Jurídico de los Funcionarios Directivos en el ámbito de la actual reforma de la Administración Pública Portuguesa \\ Luís Miguel Pereira Farinha}

Este artículo analiza las alteraciones al régimen jurídico de los funcionarios directivos de la administración pública portuguesa contenidas en la propuesta presentada por el gobierno.

También se consideran las limitaciones y los principios orientadores de la reforma.

Algunos aspectos es decir la misión del funcionario directivo, las clases y los niveles, el reclutamiento y la selección, la provisión y la duración de las comisiones de servicio y su renovación también se juzgan de un punto de vista crítico.

Finalmente se señala la importancia de monitorear la aplicación de la ley con el propósito de comprobar su papel en el cambio.

\section{The Portuguese Civil Service Managers Law changes in the scope of the current Public Administration reform}

\section{Luís Miguel Pereira Farinha}

This article examines the changes to the Portuguese Civil Service Managers Law, according to the proposal presented by the Government.

The guiding principles and the ascertained limitations are also mentioned.

Furthermore, certain details are criticised, namely, the mission of the manager, the ranks, the levels, the competencies, the training, the recruitment, the selection, the appointment, the length of the commissions and its renewal.

At last, it is stated the importance of monitoring the application of the law in order to check the role that it plays in the change.
Revista do

Serviço

Público

Ano 54

Número 4

Out-Dez 2003

Luis Miguel

Farinha é Pós-

Graduado em

Estudos

Europeus pela

Universidade

Católica

Portuguesa e

assessor do

Gabinete do

Ministro da

Agricultura,

Desenvolvimento

Rural e Pescas

de Portugal.

Contato:

1farinha@

madrp.gov.pt 
